$$
\begin{aligned}
& \text { N } \\
& \text { of Economic Sciences } \\
& \text { Working Papers } \\
& \text { No. 20/2014 (137) } \\
& \text { MARCIN BIELECKI } \\
& \text { KAROLINA GORAUS } \\
& \text { JAN HAGEMEJER } \\
& \text { KRZYSZTOF MAKARSKI } \\
& \text { JOANNA TYROWICZ }
\end{aligned}
$$

SMALL ASSUMPTIONS (CAN) HAVE A LARGE BEARING: EVALUATING PENSION SYSTEM REFORMS WITH OLG MODELS 


\title{
Small assumptions (can) have a large bearing: evaluating pension system reforms with OLG models
}

\author{
MARCIN BIELECKI \\ Faculty of Economic Sciences \\ University of Warsaw \\ e-mail: mbielecki@wne.uw.edu.pl \\ JAN HAGEMEJER \\ Faculty of Economic Sciences \\ University of Warsaw \\ National Bank of Poland \\ e-mail: jhagemejer@wne.uw.edu.pl
}

\author{
Karolina Goraus \\ Faculty of Economic Sciences \\ University of Warsaw \\ e-mail:kgoraus@wne.uw.edu.pl \\ KRZYSZTOF MAKARSKI \\ Warsaw School of Economics \\ National Bank of Poland \\ e-mail: kmakar@sgh.waw.pl
}

\author{
JOANNA TYROWICZ \\ Faculty of Economic Sciences \\ University of Warsaw \\ National Bank of Poland \\ e-mail: jtyrowicz@uw.edu.pl
}

\begin{abstract}
The objective of this paper is to inquire the consequences of some simplifying assumptions typically made in the overlapping generations (OLG) models of pension systems and pension system reforms. This literature is largely driven by policy motivations. Consequently, the majority of the papers is extremely detailed in the dimension under scrutiny. On the other hand, complexity of general equilibrium OLG modeling necessitates some simplifications in the model. We run a series of experiments in which the same reform in the same economy is modeled with six different sets of assumptions concerning the shape of the utility function, time inconsistency, bequests' redistribution, labor supply decisions and internalizing the linkage between social security contributions and benefits in these decisions as well as public spending. We find that these assumptions significantly affect both the size and the sign of the macroeconomic and welfare measures of policy effects with the order of magnitude comparable to the reform itself.
\end{abstract}

Keywords:

pension system reform, overlapping generations (OLG), defined benefit, defined contribution

JEL:

C68, E17, E25, J11, J24, H55, D72

\section{Acknowledgments:}

The support of National Center for Science (grant UMO-2011/01/D/HS4/04039) is gratefully acknowledged. Authors are would like to thank to two anonymous referees, George Kouretas, Bo Larsson, Hans Fehr, Agnieszka Borowska and the participants of Netspar 2014 (Amsterdam), ISCEF 2014 (Paris) and ICMAIF 2014 (Rethymno) for valuable comments. Usual disclaimer applies. 


\section{Introduction}

Aging and increasing longevity pose numerous threats to pension systems in many countries, which fosters research into potential pension system reforms and their outcomes. The most popular tool utilized in these studies is the overlapping generations (OLG) model, as pioneered by Auerbach and Kotlikoff (1987). After the criticism by Holzman and Stiglitz (2001), there is a growing consensus in the profession that the analyses should focus on measuring welfare effects in addition to pure macroeconomic effects. In addition, it is more and more frequent that the whole path of adjustment is analyzed, not only the initial and the final steady state.

Despite this consensus, each researcher is faced with a variety of modeling options, which all may have some - or even major - bearing on model outcomes. Modeling choices are sometimes a consequence of a need to reduce mathematical complexity. In addition, given the variety and richness of research questions formulated in various papers, it may be impossible in most of the cases to test the susceptibility of the different findings to some particular model features. The objective of this paper is to quantify the consequences of such modeling choices. To this end we construct a standard model of an economy moving from a defined benefit (DB) system to a defined contribution (DC) one with and without privatization. We calibrate the original steady state to match the properties of a Polish economy, which implemented such reform in 1999 and run a series of experiments in which we analyze the robustness of the results to the underlying assumptions. We consider six major areas of modeling choices:

- the utility function (i.e. the relative strength of the income and substitution effects);

- the time inconsistency;

- the modeling of the labor supply including the indivisibility of labor;

- the extent to which the link between labor supply and pension benefits is explicit in the optimization problem; and

- the distribution of unintentional bequests across cohorts

- the modeling of the government expenditure.

One final decision to be made by the researcher concerns the within cohort heterogeneity with idiosyncratic endowment/productivity shocks experienced by the agents. However, moving from a deterministic to a stochastic setting involves much more variations that one single assumption, which is why we restrain from comparing stochastic to deterministic model setups. The role of the stochastic (microeconomic) income shocks has been discussed at length by De Nardi et al. (1999), Nishiyama and Smetters (2005), Fehr (2009).

While many papers provide some sensitivity checks, they rarely analyze modeling alternatives. This is particularly acute in the case of deep modeling assumptions, as the five considered in our paper, because oftentimes it would require the model to be analytically solved separately for each modeling alternative. In this paper we consider a standard reform, but in a variety of modeling approaches to test quantitatively if and to what extent these modeling choices could be driving the results. To make sure that the (eventual) differences between outcomes are not driven by differences in the model parameters, when calibrating the various specifications of the model, we keep all other features of the model constant (instead we allow some - tractable - departures in the pre-reform steady state). Given the multiplicity of the analyzed specifications, we leave aside the analysis along the transition path. What we focus on is the difference between the pre-reform and post-reform steady states. If steady states differ across alternative model specifications, it is straightforward that so do the transition paths.

Given the diversity of topics, more detailed insights from the literature are discussed in the modeling section. Consequently, the structure of this paper is as follows. In the next section we present the model, emphasizing the five areas of modeling decisions which are at the core of this paper. Section 3 describes calibration procedure and the adopted parameter values. Section 4 discusses the findings of our experiments. In the concluding section we try to provide some guidance to future efforts in OLG modeling. 


\section{The Model}

Consider a deterministic closed economy overlapping generations model. Agents are born at age $j=1$ (corresponding to actual age of 21) and immediately enter the labor market. They live up to the age of $J=80$ (corresponding to actual age of 100) with unconditional survival probability $\pi_{j, t}$ decreasing with age but increasing over time. We allow for the latter to capture the phenomenon of longevity. Agents leave the labor market and effective retirement age set to replicate the data, i.e. $\bar{J}=41$. Labor supply is set to zero thereafter. Households have a flat age-productivity profile.

The model comprises of three sectors: firms, the government, who operates the pension system, and households. The government and the firm sector are the same in each specification and follow the literature standard, so our emphasis in this section is on describing in detail the literature and setups concerning the consumer side of the model.

\section{$2.1 \quad$ Firms}

The enterprise sector is modeled in a standard way and is characterized by perfect competition with a representative firm producing homogeneous output $Y_{t}$ through a Cobb-Douglas production function using capital $K_{t}$ and labor $L_{t}$.

$$
Y_{t}=K_{t}^{\alpha}\left(A_{t} L_{t}\right)^{1-\alpha}
$$

Labor is an aggregation of individual labor supplies, i.e. $L_{t}=\sum_{j=1}^{\bar{J}_{t}-1} N_{t-j} \pi_{j, t} l_{j, t}$, where $N_{t-j}$ is the size of the cohort $j$ born at time $t-j$. Capital is an aggregate of the individual savings and depreciates at the rate $d$. A $A_{t}$ denotes technology that grows at the exogenous rate $\gamma_{t}$.

\subsection{The pension system}

In each model specification the baseline scenario consists of a pay-as-you-go defined benefit system (PAYG DB), whereas the reform scenario consists of a defined contribution scheme (DC).

PAYG DB system has an exogenous contribution rate $\tau^{D B}$ and an exogenous replacement rate $\rho$ with $b_{\bar{J}, t}^{D B}=\rho \cdot w_{t-1} \cdot l_{\bar{J}-1, t-1}$, where $l_{\bar{J}-1 t-1}$ is the labor supply immediately prior to the retirement. ${ }^{1}$ The benefits are indexed annually with $25 \%$ of the payroll growth rate, which coincides in our model with the technology growth rate. The system finances the pensions paid out to the retirees by the instantaneous social security contributions. The deficit is financed by the government.

The reform consists of a switch to one of the two systems. The first one is a PAYG DC, which is often referred to as NDC. In this system instantaneous contributions finance the pension benefits, but the amount of pension benefits received is an actuarially fair function of lifetime contributions ${ }^{2}$. The second one is a funded DC, where these are actual own savings (yielding a return throughout the working period) that serve financing the pensions paid to an individual during retirement.

In the NDC system the benefits are computed at the time of retirement basing on the notional accounts as shown in the formula below:

$$
b_{\bar{J}, t}^{N D C}=\frac{\sum_{s=1}^{\bar{J}-1}\left[\Pi_{m=1}^{s}\left(1+r_{t-j+m-1}^{N D C}\right)\right] \tau_{t-j+s-1}^{N D C} w_{t-j+s-1} l_{s, t-j+s-1}}{\prod_{s=\bar{J}}^{J} \pi_{s, t}}
$$

The rate $r^{N D C}$ is specified in the legislation and amounts to the payroll growth. In the funded DC system (FDC) the accounts correspond to actual savings and at the time of retirement they are converted to an annuity:

$$
b_{\bar{J}_{t}, t}^{F D C}=\frac{\sum_{s=1}^{\bar{J}-1}\left[\Pi_{m=1}^{s}\left(1+r_{t-j+m-1}^{F D C}\right)\right] \tau_{t-j+s-1}^{F D C} w_{t-j+s-1} l_{s, t-j+s-1}}{\prod_{s=\bar{J}}^{J} \pi_{s, t}}
$$

The rate $r^{F D C}$ is equivalent to the market interest rate. According to the legislation - unlike private savings - savings in the compulsory pension system are exempt from the capital income tax.

After retirement pensions are indexed with $25 \%$ of the payroll growth in the NDC and with the endogenous market interest rate in the FDC.

\footnotetext{
${ }^{1}$ Polish legislation specifies that the replacement rate is multiplied by the average from the last ten years of activity. Our model replicates this feature.

${ }^{2}$ see Auerbach and Lee (2006) for an overview of such systems.
} 


\subsection{Consumer}

The household consists of a single person that maximizes lifetime utility derived from consumption $c$ and leisure $(1-l)$. At each time period $t$ the objective function of an agent is the present value of remaining lifetime utility:

$$
U_{j, t}\left(c_{j, t}, l_{j, t}\right)=u\left(c_{j, t}, l_{j, t}\right)+\sum_{s=1}^{J-j} \delta^{s} \frac{\pi_{j+s, t+s}}{\pi_{j, t}} u\left(c_{j+s, t+s}, l_{j+s, t+s}\right),
$$

where $\delta$ is the time discounting factor.

An agent of age $j$ in period $t$ maximizes her utility function given by (4) subject to the sequence of budget constraints:

$$
\begin{aligned}
\left(1+\tau_{c, t}\right) c_{j, t}+s_{j, t}+\Upsilon_{t} & =\left(1-\tau_{j, t}^{\iota}-\tau_{l, t}\right) w_{t} l_{j, t} \leftarrow \text { labor income } \\
& +\left(1+r_{t}\left(1-\tau_{k, t}\right)\right) s_{j, t-1} \leftarrow \text { capital income } \\
& +\left(1-\tau_{l, t}\right) b_{j, t}^{\iota}+\text { bequest }_{j, t} \leftarrow \text { pensions and bequests }
\end{aligned}
$$

where $s$ are the agent's savings, $w$ is the wage rate and the $\tau$ 's correspond to various taxes: $\tau_{c}$ is the consumption tax, $\tau_{l}$ and $\tau_{k}$ are the labor and capital income taxation, respectively, and $\tau^{\iota}$ and $b^{\iota}$ correspond to the social security contributions and pensions in the $\iota$ pension system, respectively. The $\Upsilon_{t}$ is a lump-sum tax/transfer used to calibrate the steady state budget deficit.

In the abundant literature, there is a variety of actual modeling choices to be made with reference to consumer. They concern the choice of the utility function, the extent of discounting (time inconsistency), labor supply patterns, the distribution of bequests and the extent to which agents are aware of the link between their labor supply and subsequent pensions. In the baseline model we assume that:

- instantaneous utility is given by Cobb-Douglas function (in the alternative specification we use Greenwood et al. (1988) specification, called GHH);

- agents are time consistent (in the alternative specification we allow for quasi-hyperbolic discounting);

- labor supply is perfectly elastic (in the alternative specification there are indivisible labor demand units);

- unintentional bequests are redistributed only within the same cohort (in the alternative specification we allow the bequests to be distributed universally across all cohorts);

- agents see no link between labor supply and pensions in eq. (4) (in the alternative specifications eq. (4) has a non-zero derivative of pension benefits with respect to $l_{j, t}$ );

- government expenditure is held constant in per capita terms (in the alternative specifications it is $G / Y$ ratio which is held constant).

\subsubsection{Substitution, income and wealth effects}

The field has not reached a consensus about the form of the utility function and there is a wide variety of approaches followed by specific papers. A common, but not universal choice is to adopt an enveloping CRRA function, nesting other specific intratemporal preferences. Papers dealing explicitly with non-deterministic environments tend to choose the coefficient of relative risk aversion of value 2, see Nishiyama and Smetters (2007), Fehr et al. (2008). In fully deterministic settings CRRA is often reduced to its logarithmic form. Considering the nested functions, while CES is often used, various authors employ its reduced form i.e. Cobb-Douglass preferences, as well as additive preferences (other than CES) ${ }^{3}$. Although the utility function is typically the same in the baseline and in the reform scenarios, it may still have a role to play. Namely, if pension reform

\footnotetext{
${ }^{3}$ Clearly, papers employing value functions iterations have much more flexibility in designing the functional form than the literature based on Gauss-Seidel algorithm, where closed form solution needs to be derived).
} 
affects capital accumulation, it automatically alters the relative prices of leisure and consumption. This introduces income, wealth and substitution effects, which may matter substantially for the evaluation of the policy reform.

Under the commonly employed assumption of CES preferences, as in Auerbach and Kotlikoff (1987), there is a strong link between the agents' wealth and their labor supply. The direct consequence of this assumption is (excluding the effects of mortality risk) the monotonous movement in the number of hours worked ${ }^{4}$. However, there is still ample evidence that the influence of wealth effects on labor supply decisions is not as strong as implied by the CES preferences. A significant part of the literature - e.g. Schmitt-Grohe and Uribe (2003), Monacelli and Perotti (2008), Jaimovich and Rebelo (2009), Schmitt-Grohe and Uribe (2012), Nakamura and Steinsson (2014) argues that the estimates of labor supply responses to changes in taxation are unrealistically high, and thus overstate the labor market effects of fiscal policy shifts, and suggests considering other than CES type functions.

This observation can be of crucial importance while trying to assess the effects of the pension system changes, as different pension schemes not only differ substantially in the intratemporal incentive structure, but also can generate shifts in lifetime wealth. In order to alleviate this problem, Greenwood et al. (1988) suggested an alternative utility function similar to equation 7, where $\xi$ is the inverse of Frisch elasticity of labor, and $\psi$ is a parameter describing the disutility of labor. The advantage of adopting the GHH utility comes from divorcing the intratemporal choice of labor supply from the intertemporal consumption-savings choice. This fully eliminates the wealth effect in labor supply choice, see e.g. Heer et al. (2014). Consequently, current labor supply of an agent depends only on the wage she is offered, regardless of her accrued wealth. While Blanchard (1985) argued that in general the GHH-type preferences are consistent with possible negative labor supply, adequate parametrization is able to overcome this shortcoming.

In our exercise we keep the strength of the substitution effects constant across both CobbDouglas and GHH specifications, while the strength of the income effect (which is tainted by the wealth effect under the Cobb-Douglas case) is allowed to vary freely. We find that the change in the utility function yields the most significant differences across all of the considered modeling choices, and even switches the sign of measured welfare gain/loss. The key lesson to take from the exercise is that the choice of the appropriate preference representation is of utmost importance, and that the Frisch elasticity of labor is not a sufficient statistic to pinpoint the effects of policy shifts. Summarizing, in the baseline specification, the utility function is given by

$$
u_{j}\left(c_{j, t}, l_{j, t}\right)=\ln \left[c_{j, t}^{\phi}\left(1-l_{j, t}\right)^{1-\phi}\right] .
$$

In the alternative specification, we eliminate the potential role of wealth effect, employing

$$
u_{j}\left(c_{j, t}, l_{j, t}\right)=\ln \left[c_{j, t}-\psi \cdot \gamma_{t} l_{j, t}^{1+\xi} /(1+\xi)\right] .
$$

\subsubsection{Time inconsistency}

Many welfare analyses of the pension systems show that in principle the introduction of a pension scheme is welfare deteriorating, since the pension system contributions are a distortionary tax on labor. Models with rational expectations and perfect foresight favor no pension systems, as the agents face no impediments to their optimal behavior. Even faced with demographic changes, agents with perfect foresight know that pensions will be lower or taxes higher in the future and they can voluntarily save ex ante to accommodate for these changes, see McGrattan and Prescott (2013).

On the other hand, obligatory pension systems are a disciplining mechanism, which may have particular welfare enhancing role if agents exhibit time inconsistent behavior, as first suggested by Imrohoroglu et al. (2003). This feature of the model may be particularly welcome if the original system was a defined benefit one - it might be particularly common among the consumers to keep thinking about pensions in terms of replacement rates, and not adjusting savings according to the

\footnotetext{
${ }^{4}$ The effect on the labor supply path over lifetime may be partly counteracted by the calibrated age-productivity patterns, which is sometimes pursued in the papers. Usually inverted U-shape is assumed, see Skirbekk (2004). Rojas (2005) assumes that productivity increases with work experience. For an extensive treatment of this subject, see a special issue of Labor Economics (volume 22, 2013).
} 
adverse changes in demographics and growth rates. Introducing theoretical extensions that would account for those various (but empirically indiscernible) reasons of insufficient savings, actually amplifies the gains from pension system reforms, according to Nishiyama and Smetters (2007), Fehr et al. (2008), Fehr and Kindermann (2010).

Suggesting that this was a fruitful avenue for research, Imrohoroglu et al. (2003) propose quasihyperbolic discounting

$$
U_{j}\left(c_{j, t}, l_{j, t}\right)=u_{j}\left(c_{j, t}, l_{j, t}\right)+\beta \sum_{s=1}^{J-j} \delta^{s} \frac{\pi_{j+s, t+s}}{\pi_{j, t}} u_{j}\left(c_{j+s, t+s}, l_{j+s, t+s}\right) .
$$

where $\beta$ accounts for time-inconsistency. With $\beta=1$ agents are perfectly consistent, whereas values falling short of unity imply some extent of unintentional postponing of savings and labor supply to subsequent periods. ${ }^{5}$ Theoretical insights are unidirectional: in case of higher time inconsistency a change from the DB pension system to a DC one should increase gains (reduce losses). The effects of the reform are likely to be direct (longer activity, higher savings), but are in addition bound to emerge also via general equilibrium - as time-inconsistency implies lower private savings, introducing the funded DC system results with additional efficiency gains through faster capital accumulation. Indeed, Findley and Caliendo (2012) show that under defined contribution pension system agents tend to increase their working period more than under defined benefit system (mostly due to indirect incentives, which disappear under DB). A similar pattern holds for savings, as shown by Imrohoroglu et al. (2003). Despite reducing their pre-retirement leisure and/or consumption, agents to a lesser extent experience old-age poverty, which improves social welfare.

However, it is conceptually challenging to evaluate the actual size of this effect, see Fehr et al. (2008). Namely, models typically have time preferences, $\delta$, i.e. a parameter calibrated to match the prevailing interest rate. Introducing $\beta \neq 1$ implies either re-calibrating the value of $\delta$ or accepting a different equilibrium interest rate. Thus, the modeler ends up with either different preferences or a different economy. The majority of the literature chooses the former, thus making comparisons between model specifications impossible. In this paper we do the opposite: we calibrate $\delta$ parameter without time inconsistency in the baseline scenario. Subsequently, we introduce $\beta=0.9$, but hold $\delta$ constant. Comparing the initial steady states we can tell how different these two economies are. Comparing the original and final steady states allows us to tell how large are the effects of the pension system reform under these two different assumptions concerning $\beta$. We thus subsequently compare differences in differences to gauge the effects of assuming time inconsistency on model conclusions.

\subsubsection{Employment adjustment in intensive and extensive margins}

A substantial part of the OLG literature assumes away labor market frictions. The major exception consists of encompassing search and non-pension benefits systems by Berger et al. (2009), Keuschnigg et al. (2012). Despite these efforts, to the best of our knowledge all models consider perfectly elastic labor supply and use stochastic income or search to account for periods of inactivity.

Unfortunately, this assumption is not particularly appealing with reference to most economies given that actual empirical labor supply tends to be tri-modal (with majority of people working zero, half-time or full-time), whereas elderly tend to extend the duration of economic activity working part-time rather than full-time. Heckman (1993) gives an overview of the related literature and underlines the importance of ignoring the extensive margin adjustment when analyzing aggregate labor supply response to policy changes. Blundell et al. (2013) show that in major developed countries neither of the two margins dominate the labor market adjustment, however, their relative sizes do differ by age, gender and family composition. The problem of extensive and intensive margin of labor adjustment has been considered in the literature related to analysis of public finances in the past. The early works include Diamond (1980) who considers extensive margin only (indivisible labor) and points to discontinuities in the labor supply response. Hansen (1985) shows that even with discontinuous individual labor supply choice sets, the aggregate economy can have a perfectly continuous equilibrium labor supply.

\footnotetext{
${ }^{5}$ Imrohoroglu et al. (2003) discuss various alternative specifications emphasizing that this is naive in a sense that agents do not realize their inconsistency and thus make no provisions. Alternative specifications turn timeinconsistent agents more and more forward looking, which brings the outcomes closer to ones generated by perfectly rational agents. Additional considerations of self-control preferences is offered by Kumru and Thanopoulos (2008).
} 
The labor supply decision on the part of the individual worker consists in fact of two-decisions: first, the agent decides whether to work by comparing the gains from working with the opportunity costs of doing so. Second, the level of labor supply is determined. The first decision is absent in majority of the papers: adjustments in household decision process are "smooth", i.e. everybody works. This may be overcome, using insights from Cogan (1980), who provides the theoretical foundations by relating to individual fixed cost of employment. In order to allow for intensive vs extensive margin adjustment the model comprises an opportunity cost of work in the form of a fixed-type cost measured in per period utility. An important development of Diamond (2003) makes use of a heterogeneously distributed opportunity cost of work to explain the differences in the incentive potential retirees face to postpone their retirement, and the consequent variation in the effective retirement age across agents. A recent study of Michau (2014) uses homogeneous opportunity cost and heterogeneous productivity distribution to analyze the intensive and extensive margin adjustments in the context of redistribution.

While the above developments are most welcome, it still remains to be seen whether the inclusion of the more 'realistic' aspects of labor markets impacts the aggregate behavior of the model in a significant way. In the baseline specification we consider labor supply to be perfectly elastic and unconstrained until $\bar{J}$, i.e. the retirement age. As a modification of this assumption we limit the choice set of working agents, forcing them to choose between pre-specified discrete allocations. In this particular example, agents may choose to work for $3 / 9,4 / 9,5 / 9$ or $6 / 9$ of their entire time endowment, emulating the notions of discontinuous increases from "part-time" through "full-time" to eventual "over-time".

Given that the cohorts differ in terms of size, discontinuous changes to the aggregate labor supply are likely to occur, which could substantially alter the equilibrium both directly and via general equilibrium effects. Quite importantly, the direction of the change is poorly predictable, because it depends on whether a complete cohort finds it more compelling to switch across the neighboring discrete points. The extent of the aggregate changes in our exercise may provide guidance to the authors considering inclusion of discontinuous elements of labor supply choice in their works.

\subsubsection{Internalizing pensions in labor supply decision}

When discussing the characteristics of the DB and the DC systems, the majority of the literature puts emphasis on the differences in the incentive schemes, see Diamond (1993), Diamond and Barr (2006). On the one hand, under DB systems the replacement rate is exogenous and pensions depend to a large extent on the "last" income prior to the retirement rather than lifetime contributions. On the other hand, DC systems pay out as much as was contributed during the entire working life, thus yielding incentives to raise the entire life-time labor supply. ${ }^{6}$

This effect is likely to operate, however, only if the agents see the value of benefits when determining labor supply. This implies that the derivative of benefit with respect to labor has to be non-zero, which makes the analytic solution cumbersome. Fehr (2000) offers a technical solution using implicit tax formulation. He introduces a link between the contribution rates and benefits indirectly: if entire contribution is transformed to subsequent pensions at market interest rate, then implicit social security "tax" is in fact zero. On the other hand, if benefits do not depend on the contributions (as in DB system), the entire pension contribution is in fact a (social security) tax. If the contribution rates are converted to pensions at interest rate different from the prevailing market rate, the implicit tax falls between 0 and 1, depending on the actual accrual rules ${ }^{7}$.

The solution proposed by Fehr (2000) is mathematically elegant and fairly simple (the implicit tax can be iteratively computed in the model, which implies that both Gauss-Seidel and VFI algorithms can easily implement it), but has been surprisingly often left out, see Fehr (2009) for discussion. In this paper we treat as baseline a specification in which agents see no link between the pension contributions and pension benefits, regardless of the pension system. In the alternative specification the model is equipped with the implicit tax mechanism. In the DB system the implicit tax is complete (until the last 10 years of agents' activity), but in the DC systems it is not. This is

\footnotetext{
${ }^{6}$ With endogenous retirement age, DC systems yield also incentives to extend the number of working periods, as the value of the benefits received post retirement increases with the contributions but also the shorter the duration of the retirement. This paper treats retirement age as exogenous.

${ }^{7}$ In isolated cases, the implicit tax may be in fact negative, for example when the obligatory retirement savings are exempt from regular capital taxation, as in the Polish case
} 
likely to result in large effects for the labor supply and thus a considerably different second steady state. However, despite the general equilibrium effects, it is not ex ante clear if welfare or output should be substantially changed, because the price of labor and capital will adapt as well.

\subsubsection{Bequests}

In macroeconomic models bequests are typically of secondary importance. Cohorts typically leave accidental bequests, i.e. there is no altruism motive, see Fehr and Uhde $(2013,2014) .{ }^{8}$ While usually neglected, bequests can play in principle an important role in determining the benefits or gains from the pension system reform. This follows from the fact that with perfect foresight, bequests are likely to affect savings behavior, depending on how they are distributed among the survivors. For example, if bequests are evenly distributed among all cohorts, this is similar to a lump sum transfer with effectively a strong inter-generational redistribution from the middle aged and elderly towards youth. Similarly, Sefton et al. (2008), Sefton and Van De Ven (2009) and subsequently Fehr and Uhde (2014) transfer unintentional bequests directly to the government budget, hence reducing the tax burden on taxpayers, i.e. young and future generations. On the other hand, if the bequests are distributed within cohorts, most affluent middle aged households expect relatively high transfers from the deceased within their cohort, which effectively lowers their incentives to save at this stage of life, which may subsequently translate to lower aggregate savings.

The effects of bequests differ depending on a pension scheme. Under DB or NDC pension scheme the bequests come only from unconsumed private savings, but under FDC scheme we also assume that forced savings accumulated on the pension accounts of agents who die before reaching the retirement age are also treated as unintentional bequests. Consequently, depending on the pension system, the distribution of bequests can distort the incentives for private voluntary savings, but in FDC bequests can also reduce the rate of obligatory capital accumulation.

To measure the size of this effect in evaluating the effects of the pension system reforms, we introduce two types of bequests distribution. As noted in equation (4), bequest ${ }_{j, t}$ denotes bequest that cohort $j$ receives at time $t$ from agents that died at the end of time period $t-1$. In our baseline specification bequests are distributed within the same cohort. In this situation bequests $s_{j, t}$ equals the bequests left by agents that died at the end of time period $t-1$ at the age of $j-1$. Such setting can be interpreted as leaving the bequests to spouses.

In the alternative specification bequests are uniformly distributed among all living cohorts, so $\forall_{j}$ bequest $_{j, t}=$ bequests $_{t}$. In this setting youth leave (small) bequests to the older cohorts, middle aged leave (large) bequests to young and old and finally old leave (small) bequest to everybody else. This is similar to reducing lump sum taxation in period $t$, thus resembling specifications of Sefton et al. (2008), Sefton and Van De Ven (2009), Fehr and Uhde (2014).

Switching from redistribution of bequests within the same cohort to uniformly distributed bequests may affect the gains from reforming the DB system. Firstly, moving to the DC scheme would affect different cohorts with higher or lower intensity, and the uniform redistribution of bequests could smooth or reinforce part of these effects between generations. Secondly, in the reform that also includes the introduction of funded scheme, there will be relatively big forced savings left as bequests by persons just below the retirement age.

\subsubsection{Government expenditure modeling}

The literature lacks consensus on how to model non-pension public spending in the OLG framework. There is strong insights from the Generational Accounting (GA) which emphasizes the role of longevity and aging in future government expenditure. More specifically, it is standard to simulate scenarios with increasing costs of elderly health care (and somewhat decreasing costs of youth education), yielding overall increase in government spending. Yet, OLG models typically do not place the government expenditure in the utility function, which implies that assuming higher government expenditure in the future is consistent with more pure waste in the final steady state.

In fact, treating government expenditure as waste is an industry standard in DSGE models, see Leeper (1991), and with numerous contributions such as Schmitt-Grohe and Uribe (2007), Leith

\footnotetext{
${ }^{8}$ Alternatively, bequests can be intentional, e.g. Hviding and Marette (1998), Fehr and Kindermann (2010), but then utility function departs substantially from standard formulations as discussed in section 2.3.1 For example, one may introduce a warm-glow giving, such as Andreoni (1990), Shayo (2009).
} 
and Wren-Lewis (2008), Kirsanova et al. (2009). An alternative is to place government expenditure directly in the utility function as a public good, cfr. Bi and Kumhof (2011). Finally, government expenditure may be bundled with private consumption before it enters utility, e.g. Forni et al. (2010).

The issue at hand is far from trivial. On the one hand, if we want our model economy to maintain some of the balanced growth path type features, we should strive to either hold constant the public debt to output ratio or the government expenditure to output ratio, preferably both, as is common in both DSGE and OLG literature, e.g. Imrohoroglu et al. (2003). On the other, if the economy undergoes a demographic transition, holding $G / Y$ ratio constant results in a major change in public good provision per capita. ${ }^{9}$ Consequently it might be more relevant to fix the government expenditure per capita - see Fehr et al. (2008) - disregarding the effects of such decision on the output composition. Either of the choices may significantly affect welfare even if government expenditure does not yield any direct or indirect utility.

In practical terms a demographic transition faced by our analyzed economy implies the following patterns. If $G$ is held fixed in per capita terms, public spending share in output falls by almost a half from $20 \%$ in the initial steady state to $10.5-11 \%$ in the final steady state (depending on the retirement system). Analogously, holding $G / Y$ constant results in an almost twofold increase in per capita government expenditure. In the first case, the extent of waste is reduced substantially, leaving more output to be shared between consumption and savings/investment. In the latter, the there is no effect on consumption/investment, but per capita "useless" transfer from the state is nearly twice as big. Since it is "useless" it does not offset the (lump sum) taxes levied to balance the budget.

In our setting government expenditure is pure waste. In the baseline scenario it $\mathrm{s}$ held constant in per capita terms. In the alternative specification we the government spending is exogenously determined as a fixed share of GDP, i.e. $\gamma_{G} \cdot y$. In both scenarios the general government budget is closed through the lump sum tax $\Upsilon$ and the government debt is fixed at the $45 \%$ share of GDP. Although composition effects on output may be significant, welfare could remain largely unaffected by this change if different choices of the final steady state yield similar utility to the cohorts.

\section{Calibration}

The objective of this paper is to evaluate the bearing some of the modeling assumptions may have on measuring the effects of pension system reforms in the OLG framework. We analyze a change from a DB system to a DC system. Because pay-as-you-go systems and funded systems are characterized by different mechanisms of capital accumulation, we consider these two types of reforms separately. With the variety of modeling options we consider, we need to calibrate six original steady states: a single baseline scenario and one for each of the analyzed modeling choices. As suggested already in the context of time inconsistency in section 2.3.2, one needs to be extremely careful about the calibration. If initial (steady state) economies are supposed to be identical in all specifications, preference parameters would have to differ. Alternatively, deep preference parameters could be kept constant across model specifications. In such case, post-reform steady state should each be compared to its analogous initial steady state. We follow the latter, demonstrating clearly if at all and by how much these original steady states differ under alternative assumptions options.

Although the precise calibration of any particular economy is of secondary importance to our exercise, we regard the Polish economy in year 1999 as a useful starting point, as this economy introduced a reform from a PAYG DB to a system combining NDC and FDC without altering the contribution rates. We use the actual macro- and micro-evidence for the Polish economy. Original population structure is based on census data, whereas the post-reform steady state has population structure derived from a projection by EU's Economic Policy Committee Working Group on Aging Populations and Sustainability for the year 2060. Both population structures are stationary. Figure 1 shows that the final steady state is characterized by much older generation with fewer young and higher life expectancy than the initial steady state.

\footnotetext{
${ }^{9}$ We are particularly grateful to one of the anonymous referees for bringing this point up.
} 


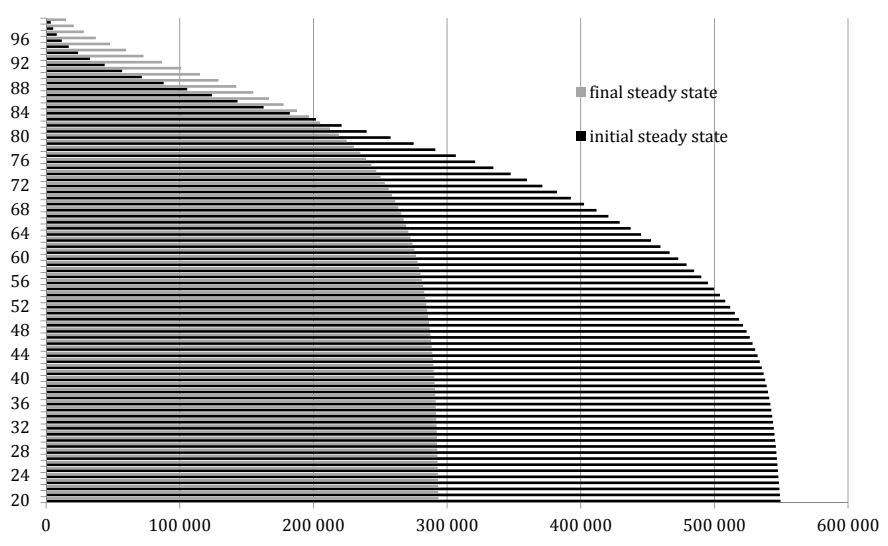

Figure 1: Initial and final steady state demographics

\subsection{Calibration in the baseline specification parameters}

In the baseline specification, consumers are perfectly rational, labor is supplied elastically, agents see no link between contributions and pension benefits, and bequests stay within the same cohort. In addition, agents have Cobb-Douglas preferences with the disutility of labor $\phi$ selected such that the employment rate matches $56.8 \%$ observed in the data. In the specification with the GHH utility function, in order to keep the influence of substitution effect constant across the different utility functions, we compute the implied Frisch elasticity of labor from our Cobb-Douglas case. ${ }^{10}$

As is standard in the literature, we assume the capital share of income $\alpha=0.3$. We set the yearly depreciation rate at $d=0.055$ to match the investment share to GDP at the $21 \%$, as is the average for 1994-2004 period. Given those parameters, we look for the discounting factor $\delta$ that allows us to match the interest rate. However, the average TFP growth rate for that economy was at vary impressive $3.8 \%$ over that period, which naturally drives the real return on capital up to $7.4 \%$ over 1994-2004. We thus chose $\delta$ to match the above interest rate.

Table 1: Calibrated technology and preference parameters

\begin{tabular}{|c|c|c|c|}
\hline & Parameters & CD & GHH \\
\hline \multicolumn{4}{|c|}{ Technology } \\
\hline$\alpha$ & capital share of income & 0.3 & 0.3 \\
\hline$d$ & depreciation rate & 0.055 & 0.055 \\
\hline \multicolumn{4}{|c|}{ Preferences } \\
\hline$\delta$ & discounting factor & 0.979 & 0.997 \\
\hline \multirow[t]{2}{*}{$1 / \xi$} & Frisch elasticity & 0.76 & 0.76 \\
\hline & labour disutility & $\phi=0.527$ & $\psi=1.735$ \\
\hline \multicolumn{4}{|c|}{ Taxes and retirement } \\
\hline$\overline{\tau^{c}}$ & consumption tax & 0.11 & 0.11 \\
\hline$\tau^{l}$ & labor income tax & 0.11 & 0.11 \\
\hline$\tau^{k}$ & capital income tax & 0.19 & 0.19 \\
\hline$\rho$ & replacement ratio & 0.25 & 0.2535 \\
\hline$\tau^{\iota}$ & contribution rate & 0.06 & 0.06 \\
\hline
\end{tabular}

Regarding the structure of taxes within the model, we match the Polish economy, which is a typical European economy. We calibrate the marginal tax rates on labor and consumption to the actual effective tax rates, resulting in an 11\% tax rate on consumption and labor income. Capital

\footnotetext{
${ }^{10}$ Under the CD nested in logarithmic utility, the Frisch elasticity is independent of $\phi$ and given by the following formula: $\eta_{C D}=(1-l) / l$. The Frisch elasticity of labor under GHH utility function is given by $\eta_{G H H}=1 / \xi$. Next we look for the labor disutility parameter $\psi$ that yields us the same employment rate as under the Cobb-Douglas case.
} 
income tax was set to de iure $19 \%$, which is roughly identical to the effective tax rate. Reflecting the long-term trends, the pure government spending share in GDP $\gamma_{G}$ was set to $20 \%$ in the initial steady state. We calibrate the two key parameters to match the Polish 1999 pay-as-you-go defined benefit system. We adjust the replacement ratio parameter $\rho$ to match the observed $5 \%$ proportion of retirement benefits to GDP, and set the contribution rate $\tau^{D B}$ such that the model generates the observed subsidy to the pension system (0.8\% share in GDP). When performing the switch to defined contribution schemes, we hold the contribution rates fixed at the level from the initial steady state.

Table 1 summarizes the calibration of the deep parameters. In order for the outcomes under GHH utility to match the desired macroeconomic variables, time discounting factor $\delta$ needs to be adjusted. To some extent also the parameters of the pension system differ between the GHH and baseline specification.

\subsection{Baseline and alternative specifications in the initial steady state}

Given the stand that we try to keep preferences constant across specifications, we first show the quality of calibrations. Table 2 reports these values. The constraints implied by various model specifications in terms of overall "impatience" are clear: with additional discounting in the case of time inconsistent consumers, interest rates tend to be much higher and - accordingly - investment rates much lower. Despite this exception, our model economies are similar, with effectively the same size of the pension system and government.

Table 2: Economy and calibrations across baseline and alternative specifications

\begin{tabular}{l||ccccccc}
\hline \hline PAYG DB & $\begin{array}{c}\text { Poland } \\
1999\end{array}$ & Baseline & $\begin{array}{c}\text { Time } \\
\text { inconsistency }\end{array}$ & $\begin{array}{c}\text { Implicit } \\
\text { tax }\end{array}$ & $\begin{array}{c}\text { Uniform } \\
\text { bequests }\end{array}$ & $\begin{array}{c}\text { Discrete } \\
\text { labor choice }\end{array}$ & $\begin{array}{c}\text { GHH } \\
\text { utility }\end{array}$ \\
\hline \hline investment rate & $21.0 \%$ & $21.0 \%$ & $19.7 \%$ & $20.6 \%$ & $21.5 \%$ & $19.9 \%$ & $21.1 \%$ \\
interest rate & $7.8 \%$ & $7.8 \%$ & $8.6 \%$ & $8.0 \%$ & $7.5 \%$ & $8.5 \%$ & $7.8 \%$ \\
benefits (as \% of GDP) & $5.0 \%$ & $5.0 \%$ & $5.0 \%$ & $5.6 \%$ & $5.1 \%$ & $5.0 \%$ & $4.9 \%$ \\
deficit (as \% of GDP) & $1.6 \%$ & $1.6 \%$ & $1.6 \%$ & $1.6 \%$ & $1.6 \%$ & $1.6 \%$ & $1.6 \%$ \\
\hline
\end{tabular}

Note: For the sake of comparability, we consider primary deficit in the economy and in the model. We do not include the alternative scenario for the government spending as it is identical to baseline in the initial steady state.

Although these differences do not seem large, they do translate to somewhat different initial steady states. Table 3 shows the comparison of levels in the initial steady state under our analyzed specifications of the model relative to the baseline specification. The differences conform with our intuition, but the key take-away concerns the size of these effects. For example, as time-inconsistent agents undervalue their old age life, they tend to consume more, saving as much as app. $9 \%$ less. With depreciation assumed the same, this translates to $6 \%$ lower investment rate but roughly the same interest rate. In total, the economy with time inconsistent preferences is about $3 \%$ smaller than the one with perfect commitment.

Table 3: Outcomes across model specifications

\begin{tabular}{l||ccccccc}
\hline \hline & $y$ & $k$ & $c$ & $i$ & $L$ & $r$ & hours \\
\hline \hline Time inconsistency & $-2.67 \%$ & $-8.64 \%$ & $2.19 \%$ & $-6.13 \%$ & $-1.33 \%$ & $0.80 \%$ & $-1.33 \%$ \\
Implicit tax & $-0.90 \%$ & $-2.96 \%$ & $0.74 \%$ & $-2.08 \%$ & $2.99 \%$ & $0.26 \%$ & $2.99 \%$ \\
Uniform bequests & $0.87 \%$ & $2.92 \%$ & $-0.73 \%$ & $2.04 \%$ & $-0.33 \%$ & $-0.25 \%$ & $-0.33 \%$ \\
Discrete labor choice & $-2.27 \%$ & $-7.35 \%$ & $1.86 \%$ & $-5.21 \%$ & $-2.17 \%$ & $0.68 \%$ & $-2.17 \%$ \\
GHH & $0.03 \%$ & $0.12 \%$ & $-0.03 \%$ & $0.08 \%$ & $0.01 \%$ & $-0.01 \%$ & $0.01 \%$ \\
\hline
\end{tabular}

Note: Percentage deviations from a baseline model specification in the initial steady state with PAYG DB pension system. We do not include the alternative scenario for the government spending as it is identical to baseline in the initial steady state.

In fact, time inconsistency yields the largest departures from the baseline specification, with alternative models having economy of roughly the same size, the same capital and similar consumption. Seeing the link between contributions and pension benefits (or rather the lack thereof 
under pre-reform PAYG DB) stimulates savings and reduces consumption by app. $2 \%$. Intergenerationally redistributive bequests, stimulate savings by app. $3 \%$ relative to the baseline where bequests remain within the dying cohort. This effect is similar to a lump sum transfer and indeed translates to slightly higher investment rates and lower consumption. Despite considerable labor adjustment with GHH preferences, price effects cancel out the increased supply of labor.

\subsection{The differences in the labor supply}

While the aggregate labor supply is matched to data across specifications, the life cycle patterns need not to be the same across the alternative specifications of the model. As discussed earlier, perfectly elastic labor supply may be an unsatisfactory way to address this issue in the OLG context, especially given the fact that the reform from DB to a DC system alters substantially the incentives to labor supply. Figure 2 depicts the initial steady state labor supply distribution across age.

Indeed, if we eliminate wealth effects from the labor-consumption choice, labor supply is flat throughout the life cycle - whether agents have time-consistent preferences or not. Similar pattern occurs in the specification with the discrete labor choice. With the wealth effects labor supply exhibits a u-shaped pattern. Similar - though flatter - effect is generated by increasing mortality risk. All these adjustments, however, are quantitatively minor when set against the case where agents internalize pension benefits in labor supply choices. In fact, as discussed earlier, the PAYG DB system sets pension benefit as a ratio to the average wage from the last ten years of activity. This gives clear incentives to the households to increase labor supply in that period only (lowering it in the rest of the working life). This is manifested in the kink in Figure 2.

Figure 2: Labor supply depending on model specification

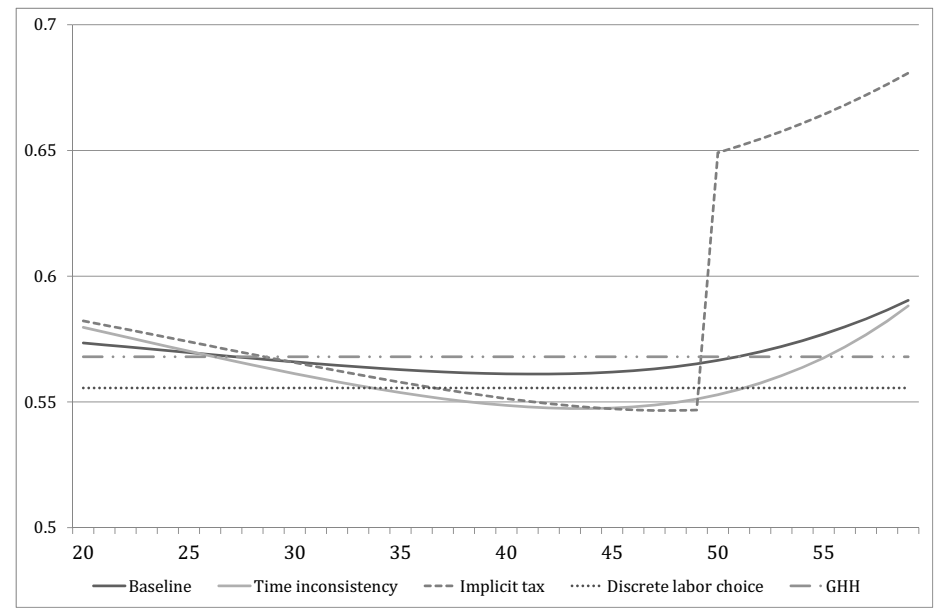

Note: We do not include the alternative scenario for the government spending as it is identical to baseline in the initial steady state.

Initial steady states are fairly similar, which would suggest that small differences in the assumptions are not that important for evaluating pension reforms. Time inconsistency clearly matters a lot for savings, but our choice here was to keep impatience constant and put inconsistency on top of time preference. Alternative approach would have been to keep overall time preference constant (a combination of impatience and time inconsistency) as has been pursued by Imrohoroglu et al. (2003). Our choice to keep $\delta$ constant is consistent with the research question: does specification (and not the preferences) affect the evaluation of the pension system reform. In the section 4 we test explicitly if the differences discussed above - seemingly predictable and innocuous - remain irrelevant in analyzing the effects of pension system reforms. However, prior to analyzing the effects of the reform, in section 3.4 we show the effects of the change in demographics and the underlying exogenous technological progress. While these two processes are universal across all the specifications of the model, the agents response need not be the same, leaving room for discrepancies in macroeconomic aggregates too. 


\subsection{The differences in the effects of demographics and technology}

The first point of reference for our analysis is the final steady state without a policy change, i.e. a DB PAYG. Changes comprise thus an aggregate reduction in population as well as a decrease in exogenous technological progress rate. This implies increased taxation to account for deteriorating the old-age dependency ratio with unchanged pension benefits (to reduce the distortionary impact of tax increase, we use lump sum tax to cover the deficit in the pension system). As a result of population change, labor supply drops by app. $40 \%$.

Thus, agents observe two changes: $K / L$ ratio increases because of demography and so do taxes. A rational response to a threat of higher taxation comprises higher savings to support consumption. This further increases savings, yielding a rise in capital per effective unit of labor increases by app. $50 \%$, Table 4. These adjustments driving up the marginal labor productivity, contributing to boosting wages. Higher capital is accompanied by an increase in hours worked to at least partially compensate for necessarily higher taxes - this pattern is true in nearly all specifications. One exception is the GHH utility function. In fact, this is very indicative of how differently a model with GHH preferences operates. First, household respond solely to a change in wages - there is no effect of increased savings on the labor supply decision. Since capital increases, labor becomes relatively more scarce, raising the price for work, thus boosting labor supply. Second, rational agents respond to expectation of higher taxes by increased individual savings. In fact, agents with $\mathrm{GHH}$ preferences raise their savings by as much as $5 \%$, which also follows from the fact that discounting is weaker (to match the data under both specifications). As a result a GHH economy ends up with a relatively low long-run interest rate. Whether or not such adjustments are a realistic approximation of what is likely to happen in reality is beyond the scope of this analysis.

Since government spending share in GDP is effectively reduced, consumption increases despite higher savings. In fact, when we analyze a scenario where $G / Y$ is held constant, consumption is lower and hours are higher to make up for the relatively large per capita public spending. This scenario yields decreased consumption and increased hours, relative to baseline, which confirms that limiting the choice set for intra and inter-temporal adjustment has a negative bearing on welfare.

Table 4: No policy reform - effects of the demographic and productivity change

\begin{tabular}{l|ccccccc}
\hline \hline PAYG DB $\Rightarrow$ PAYG DB & $y$ & $k$ & $c$ & $i$ & $L$ & $r$ & hours \\
\hline \hline \multicolumn{1}{c}{ Final steady state wrt: } & \multicolumn{1}{c}{ initial steady state (analogous specification) } & \\
\hline Baseline & $12.5 \%$ & $48.1 \%$ & $14.7 \%$ & $1.9 \%$ & $-46.2 \%$ & -3.19 & $-1.2 \%$ \\
Time inconsistency & $12.0 \%$ & $46.0 \%$ & $14.7 \%$ & $0.9 \%$ & $-46.2 \%$ & -3.29 & $-1.2 \%$ \\
Implicit tax & $12.2 \%$ & $46.6 \%$ & $14.8 \%$ & $1.2 \%$ & $-45.7 \%$ & -3.18 & $-0.2 \%$ \\
Uniform bequests & $11.9 \%$ & $45.7 \%$ & $15.1 \%$ & $0.7 \%$ & $-46.1 \%$ & -3.01 & $-1.1 \%$ \\
Discrete labor choice & $13.0 \%$ & $50.3 \%$ & $14.4 \%$ & $3.0 \%$ & $-45.5 \%$ & -3.29 & $0.0 \%$ \\
Constant $G / Y$ & $13.2 \%$ & $51.0 \%$ & $-1.2 \%$ & $3.3 \%$ & $-43.0 \%$ & -3.32 & $4.7 \%$ \\
GHH & $14.0 \%$ & $54.8 \%$ & $13.8 \%$ & $5.1 \%$ & $-39.8 \%$ & -3.49 & $10.5 \%$ \\
\hline
\end{tabular}

$\overline{\overline{\text { Note: }} \text { For the sake of comparability, we report } y, k, i \text { and } c \text { as stationary values per effective }}$ unit of labor. Differences in $r$ reported in percentage points.

These were the general macroeconomic effects of aging and longevity in our model. The interest of this paper lies in the differences across specifications. There seems to be two major sources of differences between baseline growth paths: one is the adjustment of savings (intertemporal adjustment) and the second is the adjustment of labor supply (intratemporal adjustment). An example of the first type of adjustment is in an economy with time inconsistent agents. Such agents adjust their savings as a response to decreasing income by less than the agents in the baseline specification. As a result, the long run levels of capital per worker are lower. Similar reasoning holds for the tackling of the bequests by the model: the uniform distribution of bequests dampens the effects of higher lump sum tax, thus reducing the adjustments in the economy and yielding a stunning increase in consumption (as well as an increase in capital and output). Furthermore, because there is no change in the link between pension contributions and pension benefits, the only discrepancies to baseline model here stem from general equilibrium effects. In the case of discontinuous labor supply, the key part of the result follows from possible overshooting or undershooting in labor decision due to the lack of "preferred" alternatives in the actual choice set.

Importantly, when agents do not account for wealth effects in labor-consumption choices, labor 
is reduced by substantially less with only a higher accumulation of savings. In other words, agents with GHH preferences, who respond only to wages in labor supply decisions, increase hours by much more than agents who also account for accumulated savings. Similar reasoning holds for the tackling of the bequests by the model: the uniform distribution of bequests dampens the effects of higher lump sum tax, thus reducing the adjustments in the economy and yielding a stunning increase in capital and output. Furthermore, because there is no change in the link between pension contributions and pension benefits, the only discrepancies to baseline model here stem from general equilibrium effects. In the case of discontinuous labor supply, the key part of the result follows from possible overshooting or undershooting in labor decision due to the lack of "preferred" alternatives in the actual choice set.

Given these findings one would expect that the reform has weaker effects on savings when agents receive windfall gains (such as uniform bequests) or when they are perfectly elastic and do not fully account for the future. Agents who internalize the incentives from the pension system reform to a larger extent, should see a larger increase in capital, accompanied with a larger change in labor supply. Depending on the presence of the income effect in the labor-consumption choice, the sign of labor adjustment should differ. In terms of welfare, we expect higher change in the specifications where the incentives from the change in the pension system can materialize fully. By the same token, agents with GHH preferences should increase both savings and labor supply, which is not likely to yield a welfare gain.

\section{The effects of the pension system reform in alternative specifications}

The reform scenario involves replacing a relatively generous DB system with either NDC or FDC, yielding much lower pensions. In response to lower pensions agents adapt by increasing private savings, thus contributing to higher capital (per effective unit of labor) and - directly - higher output, Table 5. The effects for capital accumulation should be highest in FDC system where the translation of the incentives is the strongest, i.e. in the following two of the analyzed cases. First, when agents see the link between the pension contributions and pension benefits. Second, when there is no wealth effect at play, i.e. with the GHH preference. We discuss the results in two substantive parts. First, we provide the overall mechanics of the reform and present the its welfare in reference to an analogous baseline specification. We do that for both analyzed types of reforms, i.e. change from PAYG DB to a NDC scheme and to a FDC one. Second, we analyze in detail the macroeconomic effects, showing how different model specifications result in different adjustments to the same reform.

To assess the effects of pension system changes, we compute a welfare change between the baseline and reform scenarios, measured as equivalent variation. This measure tells us whether a reform case yields higher utility than the baseline final steady state. Formally, equivalent variation is obtained by finding a value of $\mu$ such that the lifetime utility derived from the new consumption bundle is the same as from the old bundle (computed at $j=1$ ):

$$
U_{1}\left((1+\mu) \tilde{c}_{j}^{N R}, \tilde{l}_{j}^{N R}\right)=U_{1}\left(\tilde{c}_{j}^{R}, \tilde{l}_{j}^{R}\right),
$$

where $N R$ denotes the final steady state without a reform (i.e. PAYG DB) and $R$ denotes a postreform final steady state. As is common in the literature, $\tilde{c}=\left(c_{1}, c_{2}, \ldots, c_{J}\right)$ and $\tilde{l}=\left(l_{1}, l_{2}, \ldots, l_{J}\right)$ denote lifetime consumption stream and labor supply path, respectively. The positive value of $\mu$ signals a welfare improvement thanks to the reform.

Although we model the same reform implemented on the same economy, there are substantial differences in sign and size of the overall welfare effect, as depicted by Figure 3, where we plot the baseline model and the six alternative specifications. In general, in our case introducing a reform is welfare enhancing - whether or not a pre-funded pillar is established. Yet, the effects without a capital pillar are systematically smaller than the ones with pre-financing. Also, the effects may differ by as much as a factor of two. Finally, an economy with GHH preferences observes a welfare loss rather than a welfare gain. We discuss these three main aspects in detail below.

In the model specification with GHH preferences, pension system reform implies welfare deterioration in the case of FDC and virtually no welfare change under NDC. There are two sources of 
such welfare implications: the labor response and the difference in the weaker preference for presence, i.e. from the interplay between income and substitution effects we discussed in section 2.3.1. Under Cobb-Douglas preferences the income and the wealth effect cancel out in determining the labor supply. On the other hand, with GHH preferences, higher capital accumulation (due to higher savings to offset lower pensions and - also - due to the pre-funded pillar) yields substantially higher wages which raises the labor supply. An increase in wages which translates to an overall increase in labor supply makes thus pension system reform unfavorable. In addition to working more (and saving more), GHH households also suffer more from lowered pensions because they discount less than Cobb-Douglas households (pensions decrease when PAYG DB is replaced with any defined contribution scheme due to longevity). In order to support old-age consumption GHH agents tend to save much more over their life cycle, which further reduces interest rates and increases wages. When comparing NDC to FDC for GHH agents, lower interest rates result in further deterioration of pensions in the latter.

Figure 3: Welfare effect of the reform

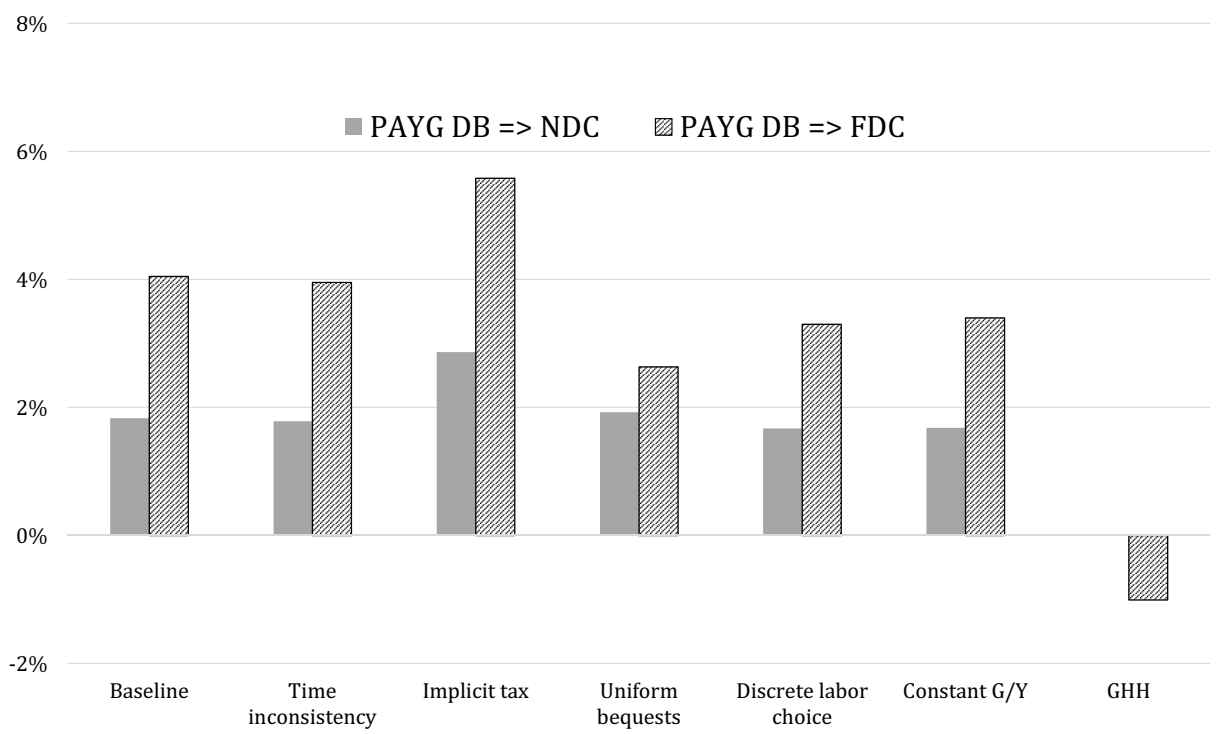

When one compares the results of the reform to NDC and FDC, there is a striking persistence of stronger welfare change for capital-based systems. The differences come mainly from the design of both systems: while NDC accounts and pensions are indexed with the growth of labor productivity (exogenous and fixed across the specifications), FDC accounts are indexed with an endogenous interest rates. Under Cobb-Douglas the interest rate remains considerably above the indexation of NDC and agents enjoy higher relative pensions and welfare gains. However, under GHH where capital accumulation is very high, interest rates are low and the small premium of FDC pension is not enough to compensate the disutility of high labor supply.

For other specifications, although the signs do not differ from the baseline, magnitudes indeed do. Contrary to the literature, time inconsistency is not quantitatively important. While a specification with time inconsistency does not seem to deviate much from the baseline in terms of welfare, it is likely to do so in terms of savings (and thus capital as well as capital/labor ratio). Agents with unsophisticated propensity to delay, indeed do save less and work less relative to the baseline specification with perfect commitment. But since it is to a similar extent true for the scenario of no policy reform and for the scenario of FDC or NDC reform, time inconsistency provides similar conclusions concerning the effects of the reform as the baseline model. This finding is in contrast to Imrohoroglu et al. (2003) as well as Fehr et al. (2008), who find that time inconsistency can have a large bearing on the evaluation of the welfare effects of pension system reforms. Yet, it seems that these conclusions were rather driven by re-calibrating the model to match the data with non-unitary $\beta$ than from the time inconsistency itself.

The welfare gains are the highest in the specification where agents see the link between pension contributions and pension benefits (the implicit tax case). This gain comes from the fact that 
Table 5: Macroeconomic effects of the reform

\begin{tabular}{|c|c|c|c|c|c|c|c|c|}
\hline & $y$ & $k$ & $c$ & $i$ & $L$ & $r$ & hours & $\mu$ \\
\hline & \multicolumn{8}{|c|}{ PAYG DB $\Rightarrow$ NDC } \\
\hline Baseline & $1.3 \%$ & $4.4 \%$ & $-0.8 \%$ & $3.1 \%$ & $-0.8 \%$ & -0.30 & $-0.8 \%$ & $1.8 \%$ \\
\hline Time inconsistency & $1.2 \%$ & $4.0 \%$ & $-0.6 \%$ & $2.8 \%$ & $-0.8 \%$ & -0.29 & $-0.8 \%$ & $1.8 \%$ \\
\hline Implicit tax & $2.5 \%$ & $8.5 \%$ & $-1.4 \%$ & $5.9 \%$ & $-3.0 \%$ & -0.57 & $-3.0 \%$ & $2.9 \%$ \\
\hline Uniform bequests & $1.5 \%$ & $5.0 \%$ & $-0.9 \%$ & $3.4 \%$ & $-0.8 \%$ & -0.33 & $-0.8 \%$ & $1.9 \%$ \\
\hline Discrete labor choice & $1.4 \%$ & $4.7 \%$ & $-0.8 \%$ & $3.3 \%$ & $-0.1 \%$ & -0.31 & $-0.1 \%$ & $1.7 \%$ \\
\hline Constant $G / Y$ & $1.6 \%$ & $5.4 \%$ & $-1.4 \%$ & $3.8 \%$ & $-0.6 \%$ & -0.36 & $-0.6 \%$ & $1.7 \%$ \\
\hline \multirow[t]{2}{*}{ GHH } & $2.4 \%$ & $8.1 \%$ & $-1.5 \%$ & $5.6 \%$ & $1.8 \%$ & -0.52 & $1.8 \%$ & $0.0 \%$ \\
\hline & \multicolumn{8}{|c|}{$\mathrm{PAYG}$ DB $\Rightarrow$ FDC } \\
\hline Baseline & $3.3 \%$ & $11.5 \%$ & $-2.0 \%$ & $7.9 \%$ & $-1.7 \%$ & -0.74 & $-1.7 \%$ & $4.0 \%$ \\
\hline Time inconsistency & $2.9 \%$ & $10.1 \%$ & $-1.6 \%$ & $6.9 \%$ & $-1.7 \%$ & -0.70 & $-1.7 \%$ & $4.0 \%$ \\
\hline Implicit tax & $4.8 \%$ & $16.9 \%$ & $-2.8 \%$ & $11.5 \%$ & $-0.6 \%$ & -1.07 & $-0.6 \%$ & $5.6 \%$ \\
\hline Uniform bequests & $2.1 \%$ & $7.1 \%$ & $-1.3 \%$ & $4.9 \%$ & $-1.1 \%$ & -0.47 & $-1.1 \%$ & $2.6 \%$ \\
\hline Discrete labor choice & $2.8 \%$ & $9.5 \%$ & $-2.2 \%$ & $6.6 \%$ & $-0.6 \%$ & -0.61 & $-0.6 \%$ & $3.3 \%$ \\
\hline Constant $G / Y$ & $4.1 \%$ & $14.4 \%$ & $-3.7 \%$ & $9.9 \%$ & $-1.3 \%$ & -0.89 & $-1.3 \%$ & $3.4 \%$ \\
\hline GHH & $6.4 \%$ & $23.0 \%$ & $-4.2 \%$ & $15.6 \%$ & $4.8 \%$ & -1.32 & $4.8 \%$ & $-1.0 \%$ \\
\hline
\end{tabular}

Note: For the sake of comparability, in both the top and the bottom panel of Table 5 we report $y, k, i$ and $c$ as stationary values per effective unit of labor. Differences in $r$ reported in percentage points.

social security contributions are in its form distortionary, as their affect the relative price of labor compared to a tax-less economy. Whenever agents observe that social security contributions are not taxes but rather a form of savings, this distortion is gone thanks to the optimal adjustment of private savings. Therefore the agent-perceived wage is in fact a „distortion-free” wage.

Uniform bequests yield smaller welfare gains under both NDC (where private savings matter less) and under FDC (where private savings for the survivors matter more). In "real world" there are either clear bequests motives (whatever they would be for an agent to draft a last will) or legislation, which stipulates the redistribution of wealth among the survivors. In OLG modeling, it is often raised that any specific rule introduces additional source of distortion, but there are two popular solutions: uniform redistribution and annuities with perfect insurance. In our baseline specification, bequests are transferred to the survivors of the same age, whereas in the additional model specification we follow the industry standard of universal bequests redistribution. Since both savings and mortality are fairly low in Poland (and in our model economies), we did not expect any large effects. When the role of private savings becomes larger - i.e. with the FDC reform - a model with uniform bequests provides the least welfare gains (of all the welfare improving), least output gain and least capital accumulation. Thus it seems that this model choice is the least favorable to privatization of the social security. The result stems from the fact that uniform bequests are the most redistributive ones (taking the most from the richest, who happen to be the generations just prior to the retirement and providing relatively the most to the poorest, who happen to be the very young and the very old). Perfect annuity mechanism would work the same way.

In the case with a discrete labor supply FDC reform has somewhat smaller welfare gain than the baseline because agents cannot fully internalize the incentives to supply labor that would follow from a change in a pension system. Agents whose labor choices are constrained tend to reduce consumption less, at the expense of optimality (welfare gain is lower than in the baseline model specification). This may suggest that frictions translate to a larger extent to the welfare analysis than to the aggregate macroeconomic effects. We interpret that as a fairly strong argument for policy relevance of this model feature.

Whether the government expenditure is anchored at households or at GDP does not seem to largely drive the welfare effects of the pension system reform. This is true for both analyzed reforms, i.e. also when the pre-funded pillar is established. ${ }^{11}$ Yet, the macroeconomics differs substantially if $G / Y$ ratio is held constant (rather than keeping per capita spendings constant). First, when prefunded pillar is established, more individual income is directed to savings and less to consumption

\footnotetext{
${ }^{11}$ Please note that this paper does not analyze the transition path, where potential welfare effects of forming the pre-funded pillar could be large.
} 
than in the baseline scenario. On the other hand, with NDC this pattern is much weaker. This is because the interest rate is much lower in the scenario with $G / Y$ held constant, which necessitates higher savings to secure the same old-age consumption. In fact, this mechanism drives the welfare gain relative to baseline.

\section{Conclusions}

OLG models, as all general equilibrium settings, are fairly complex from an analytical perspective. While thirty years of research has blossomed in a variety of model setups and a rich tool set on how to model each isolated aspect of an OLG model, in practice researchers necessarily introduce simplifications in many areas when analyzing some particular aspect of the pension system reforms. Typically, assumptions about the features of the models which are not directly related to the pension system design receive less attention and thus less robustness checks. The objective of this paper was to quantify the bearing of these "minor" assumptions on the model conclusions.

We have constructed a number of experiments where we compare always the same reform in (roughly) the same economy, but with varying model setups. We calibrate the initial steady state to match the properties of a Polish economy, which underwent a change from a PAYG DB scheme to a DC one combining two pillars: PAYG and funded. Establishing the initial steady state with PAYG DB we seek two post-reform steady states: one with funded DC and one with PAYG DC. We repeat this exercise across various model specifications in order to capture the role of the model assumptions on the evaluation of the pension system reforms.

We selected the alternative specifications in response to the literature. In fact, conference participants, referees and readers tend to ask about the susceptibility of the paper findings in five basic areas, arguing that they could be particularly important for evaluating the effects of pension system reforms. First argument raised concerns about the interplay between the reform and the wealth effect. With standard Cobb-Douglas utility function a reform which increases individual wealth has peculiar effects for the incentives to provide labor supply due to the wealth channel. We use a formulation of a utility function proposed by Greenwood et al. (1988), which has no wealth effects in labor supply decisions. To the best of our knowledge, such comparison is absent from the literature. Second, agents with time inconsistent preferences will tend to under-save, which brings about the point of potential gains from an external disciplining device. Similar to Fehr et al. (2008) we compare the effects of the reform with and without quasi-hyperbolic discounting, putting the difference yielded by this element in perspective with other modeling choices. Third, we offer a novel insight which combines the literature on discrete labor choice and OLG modeling. In fact, if labor market imperfections are accounted for, it is usually via a complex implementation of search frictions. To the best of our knowledge, there are no attempts to evaluate how much this effect matters for the evaluation of the pension system reforms. Four, although pension reforms are often about changing the incentives for work and savings, due to mathematical complexity, often agents in OLG models do not internalize future benefits in contemporaneous labor supply decisions. We capture how much bearing this simplification has on the reform evaluation. Finally, whatever the choice concerning the distribution of bequests in the model, typically a question is raised what bearing this modeling choice has on the final outcomes. Indeed, some of the ways to redistribute unintentional bequests may be more favorable to DC schemes, whereas others to DB ones. We measure how much it matters for the evaluation of the reform.

Our results show that these "minor" assumptions can do as much as to change the sign of the welfare measure. Also, even if aggregate change in capital (and thus output) are roughly the same across specifications, particular features of the models relate to opposite mechanisms of adjustment, thus raising important concerns about the policy relevance of said features of the pension system reform. We find that uniform distribution of bequests tends to be unfavorable to the evaluation of a FDC reform. So are utility functions with little or no wealth effect. On the other hand, if agents internalize the pension benefits in the labor market choices, the reform improving the alignment of macro and micro-level incentives tend to perform better. Our results show that although time inconsistency is important for determining the equilibrium of an economy, it does not change much the evaluation of the pension system reform. We also tend to conclude that the applicability ofGreenwood et al. (1988) preferences to modeling pension system reform is limited. While it offers an attractive way to eliminate the wealth effect and posits a plausible channel of 
the interplay between wages and labor supply, calibrating it to actual economy yields substantially weaker discounting. We demonstrate that an economy with Greenwood et al. (1988) preferences has an extremely strong response to a pension system reform, with substantially increased savings and labor supply. Relying on Greenwood et al. (1988) preferences should thus first be motivated by data supporting such behavioral patterns.

With this paper we aim to provide some guidance in terms of modeling choices, especially for policy purposes. We show that some of the model assumptions - on top of being favored or neglected in the literature - have a quantitatively important bearing on the conclusions concerning the welfare and the macroeconomic effects of the pension system reforms. Unlike empirical econometric studies, OLG simulations can "tell ex ante" if the reform is welfare enhancing and good for the economy. If this is the objective for which model is constructed, relying on the "least favorable" set of assumptions puts the researcher and the policy maker on the safer side of this informed guess. 


\section{References}

Andreoni, J.: 1990, Impure Altruism and Donations to Public Goods: A Theory of Warm-Glow Giving?, Economic Journal 100(401), 464-77.

Auerbach, A. J. and Lee, R.: 2006, Notional Defined Contribution Pension Systems in a Stochastic Context: Design and Stability, NBER Working Papers 12805, National Bureau of Economic Research, Inc.

Auerbach, A. and Kotlikoff, L. J.: 1987, Dynamic Fiscal Policy, Cambridge University Press.

Berger, J., Keuschnigg, C., Keuschnigg, M., Miess, M., Strohner, L. and Winter-Ebmer, R.: 2009, Modelling of Labour Markets in the European Union Final Report Part II - Documentation of the Model, mimeo, Institute for Advanced Studies, University of St. Gallen.

Bi, H. and Kumhof, M.: 2011, Jointly optimal monetary and fiscal policy rules under liquidity constraints, Journal of Macroeconomics 33(3), 373-389.

Blanchard, O. J.: 1985, Debt, Deficits, and Finite Horizons, Journal of Political Economy 93(2), 223-47.

Blundell, R., Bozio, A. and Laroque, G.: 2013, Extensive and Intensive Margins of Labour Supply: Work and Working Hours in the US, the UK and France, Fiscal Studies 34(1), 1-29.

Cogan, J. F.: 1980, Fixed Costs and Labor Supply, NBER Working Papers 0484, National Bureau of Economic Research, Inc.

De Nardi, M., Imrohoroglu, S. and Sargent, T. J.: 1999, Projected U.S. Demographics and Social Security, Review of Economic Dynamics 2(3), 575-615.

Diamond, P.: 1980, Income taxation with fixed hours of work, Journal of Public Economics 13(1), 101-110.

Diamond, P.: 1993, Privatization of Social Security: Lessons from Chile, National Bureau of Economic Research Working Paper Series 4510.

Diamond, P. A.: 2003, Taxation, Incomplete Markets, and Social Security, Vol. 1 of MIT Press Books, The MIT Press.

Diamond, P. and Barr, N.: 2006, (UBS Pensions Series 041) The Economics of Pensions, FMG Discussion Papers DP563, Financial Markets Group.

Fehr, H.: 2000, Pension reform during the demographic transition, The Scandinavian Journal of Economics 102(3), 419-443.

Fehr, H.: 2009, Computable stochastic equilibrium models and their use in pension-and ageing research, De Economist 157(4), 359-416.

Fehr, H., Habermann, C. and Kindermann, F.: 2008, Social security with rational and hyperbolic consumers, Review of Economic Dynamics 11(4), 884-903.

Fehr, H. and Kindermann, F.: 2010, Pension funding and individual accounts in economies with life-cyclers and myopes, CESifo Economic Studies 56(3), 404-443.

Fehr, H. and Uhde, J.: 2013, On the optimal design of pension systems, Empirica 40(3), 457-482.

Fehr, H. and Uhde, J.: 2014, Means-Testing Retirement Benefits in the UK: Is it Efficient?, mimeo, Netspar Discussion Paper.

Findley, S. and Caliendo, F. N.: 2012, Time-Inconsistency and Retirement Choice, Mimeo.

Forni, L., Gerali, A. and Pisani, M.: 2010, The macroeconomics of fiscal consolidations in euro area countries, Journal of Economic Dynamics and Control 34(9), 1791-1812. 
Greenwood, J., Hercowitz, Z. and Huffman, G. W.: 1988, Investment, Capacity Utilization, and the Real Business Cycle, American Economic Review 78(3), 402-17.

Hansen, G. D.: 1985, Indivisible labor and the business cycle, Journal of Monetary Economics 16(3), 309-327.

Heckman, J. J.: 1993, What Has Been Learned about Labor Supply in the Past Twenty Years?, American Economic Review 83(2), 116-21.

Heer, B., Rohrbacher, S. and Scharrer, C.: 2014, Aging, the Great Moderation and Business-Cycle Volatility in a Life-Cycle Model, CESifo Working Paper Series 4584, CESifo Group Munich.

Holzman, R. and Stiglitz, J. E.: 2001, New ideas about old age security, Washington, DC: World Bank.

Hviding, K. and Marette, M.: 1998, Macroeconomic effects of pension reforms in the context of ageing populations: Overlapping generations model simulations for seven OECD countries, OECD Economics Department Working Paper 201, OECD Publishing.

Imrohoroglu, A., Imrohoroglu, S. and Joines, D. H.: 2003, Time-Inconsistent Preferences and Social Security, The Quarterly Journal of Economics 118(2), 745-784.

Jaimovich, N. and Rebelo, S.: 2009, Can News about the Future Drive the Business Cycle?, American Economic Review 99(4), 1097-1118.

Keuschnigg, C., Davoine, T. and Schuster, P.: 2012, Aging and pension reform, a general equilibrium approach - background paper for the ECA Old-Age Insurance report - Final report, Background paper for the ECA Old-Age Insurance report - Final report, European Comission.

Kirsanova, T., Leith, C. and Wren-Lewis, S.: 2009, Monetary and Fiscal Policy Interaction: The Current Consensus Assignment in the Light of Recent Developments, Economic Journal 119(541), F482-F496.

Kumru, Ç. S. and Thanopoulos, A. C.: 2008, Social security and self control preferences, Journal of Economic Dynamics and Control 32(3), 757-778.

Leeper, E. M.: 1991, Equilibria under 'active' and 'passive' monetary and fiscal policies, Journal of Monetary Economics 27(1), 129-147.

Leith, C. and Wren-Lewis, S.: 2008, Interactions between monetary and fiscal policy under flexible exchange rates, Journal of Economic Dynamics and Control 32(9), 2854-2882.

McGrattan, E. R. and Prescott, E. C.: 2013, On financing retirement with an aging population, Working Paper 18760, National Bureau of Economic Research.

Michau, J.-B.: 2014, Optimal redistribution: A life-cycle perspective, Journal of Public Economics 111(C), 1-16.

Monacelli, T. and Perotti, R.: 2008, Fiscal Policy, Wealth Effects, and Markups, NBER Working Papers 14584, National Bureau of Economic Research, Inc.

Nakamura, E. and Steinsson, J.: 2014, Fiscal stimulus in a monetary union: Evidence from us regions, American Economic Review 104(3), 753-92.

Nishiyama, S. and Smetters, K.: 2005, Consumption taxes and economic efficiency with idiosyncratic wage shocks, Journal of Political Economy 113(5), 1088-1115.

Nishiyama, S. and Smetters, K.: 2007, Does Social Security Privatization Produce Efficiency Gains?, The Quarterly Journal of Economics 122, 1677-1719.

Rojas, J. A.: 2005, Life-cycle earnings, cohort size effects and social security: a quantitative exploration, Journal of Public Economics 89(2), 465-485. 
Schmitt-Grohe, S. and Uribe, M.: 2003, Closing small open economy models, Journal of International Economics 61(1), 163-185.

Schmitt-Grohe, S. and Uribe, M.: 2007, Optimal simple and implementable monetary and fiscal rules, Journal of Monetary Economics 54(6), 1702-1725.

Schmitt-Grohe, S. and Uribe, M.: 2012, What's news in business cycles, Econometrica 80(6), 27332764 .

Sefton, J. and Van De Ven, J.: 2009, Optimal design of means tested retirement benefits*, The Economic Journal 119(541), F461-F481.

Sefton, J., Van de Ven, J. and Weale, M.: 2008, Means testing retirement benefits: fostering equity or discouraging savings?*, The Economic Journal 118(528), 556-590.

Shayo, M.: 2009, A model of social identity with an application to political economy: Nation, class, and redistribution, American Political Science Review 103, 147-174.

Skirbekk, V.: 2004, Age and individual productivity: A literature survey, Vienna yearbook of population research pp. 133-153. 


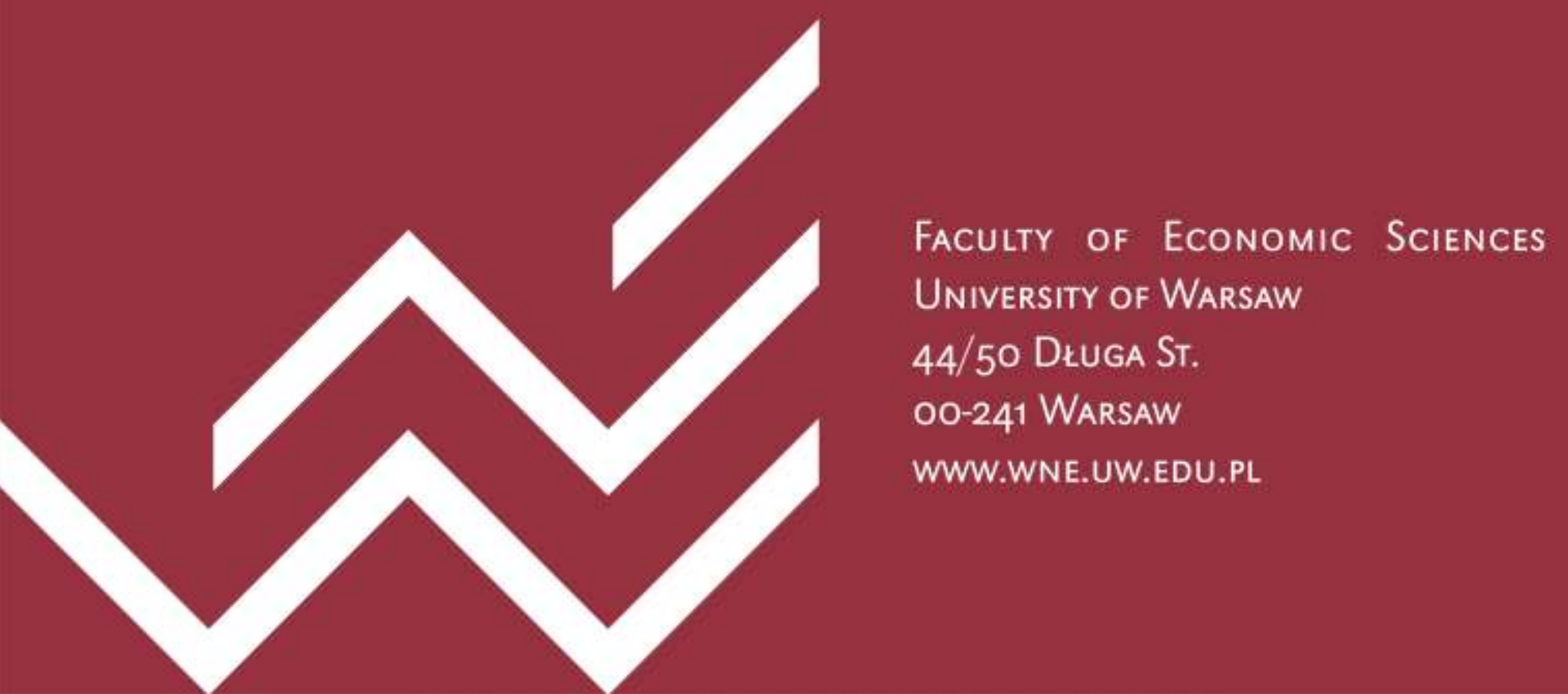

